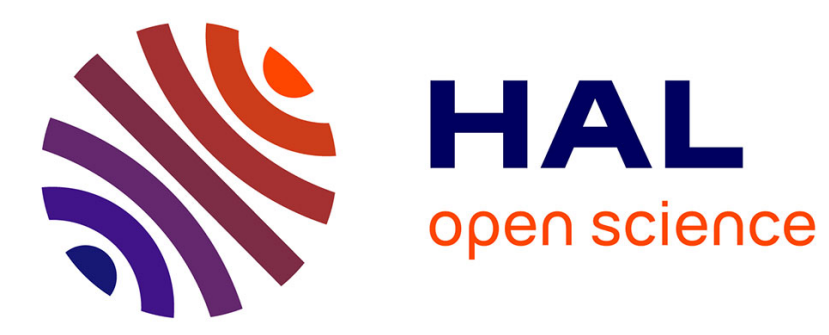

\title{
COLLECTIVE EFFECTS IN THE DESORPTION PROCESS INDUCED BY Hn+ CLUSTERS NEAR THE BOHR'S VELOCITY
}

\author{
J.-P. Thomas, A. Oladipo, M. Fallavier
}

\section{- To cite this version:}

J.-P. Thomas, A. Oladipo, M. Fallavier. COLLECTIVE EFFECTS IN THE DESORPTION PROCESS INDUCED BY Hn+ CLUSTERS NEAR THE BOHR'S VELOCITY. Atomic Physics For Ion Driven Fusion 4, 1988, Orsay, France. pp.C2-195-C2-203, 10.1051/jphyscol:1989233 . jpa-00229431

\section{HAL Id: jpa-00229431 https://hal.science/jpa-00229431}

Submitted on 1 Jan 1989

HAL is a multi-disciplinary open access archive for the deposit and dissemination of scientific research documents, whether they are published or not. The documents may come from teaching and research institutions in France or abroad, or from public or private research centers.
L'archive ouverte pluridisciplinaire HAL, est destinée au dépôt et à la diffusion de documents scientifiques de niveau recherche, publiés ou non, émanant des établissements d'enseignement et de recherche français ou étrangers, des laboratoires publics ou privés. 


\title{
COLLECTIVE EFFECTS IN THE DESORPTION PROCESS INDUCED BY Hn ${ }^{+}$CLUSTERS NEAR THE BOHR'S VELOCITY
}

\author{
J.P. THOMAS, A. OLADIPO and M. FALLAVIER \\ Institut de Physique Nucléaire de Iyon, Université Claude Bernard Lyon- \\ 1. 43, Bd du 11 Novembre 1918, F-69622 Villeurbanne Cedex, France
}

\begin{abstract}
Résumé - Le rendement d'émission des ions positifs $\mathrm{Cs}^{+}$et $\mathrm{H}^{+}$émis à partir de CsI sous I'impact d'agrégats $\mathrm{H}^{+}$d'énergie maximale $600 \mathrm{keV}$ a été corrélé au dépôt d'énergie de ces

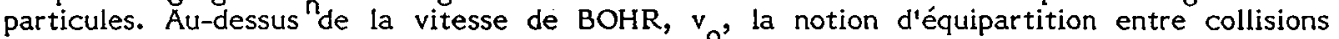
proches et lointaines apparait applicable alors qu'au-dessous de $v_{0}$ on constate une persistance des effets collectifs (collisions distantes). Une même relation puissance est observée entre le rendement d'émission et le pouvoir d'arrêt moyen " efficace " pour l'agrégat sur tout le domaine de vitesse exploré.
\end{abstract}

Abstract - The emission yield of the positive ions $\mathrm{Cs}^{+}$and $\mathrm{H}^{+}$from CsI bombarded by $600 \mathrm{keV}$ $\mathrm{H}_{\mathrm{n}}{ }^{+}$clusters, has been correlated with the energy deposited by these particles. Above the BOHR'S velocity, $v_{o}$, the concept of equipartition between close and distant collisions could apply while below $v_{0}$, collective effects are still observed (distant collisions). The same power relationship between the emission yield and an " efficent " mean stopping power for the cluster is pointed out within the whole investigated velocity range.

\section{1 - INTRODUCTION}

The recent use of fast (electronic stopping) clusters or molecular ions for inducing sputtering or desorption from insulating materials, has clearly pointed out a non linear enhancement of the secondary ion emission yield per individual component. This has firstly been observed in the laboratory $/ 1 / / 2 /$ with hydrogen clusters when relating the electronic additive stopping power to the yield and obtaining a fourth power dependence. Later on, such a non linearity has been reported for heavier molecular ions $/ 3 / / 4 /$. Since our first approach to the stopping power for a $\mathrm{H}^{+}$cluster $/ 2 /$, we intend to develop in this paper the concept of variable energy deposit along the trajectory of the projectile. Experiments performed both above and below the BOHR'S velocity, v, support this concept and lead to some new hypothesis about the validity of the equipartition rule early investigated by BRANDT and RITCHIE / $/$ for small clusters, above $v_{\odot}$. The yield variation can be related to an " efficent " mean stopping for the cluster from experiments at constant velocity or when varying the velocity for a given cluster mass. This has been done for the $\mathrm{Cs}^{+}$emission from CsI. On the same 'material we have also investigated the peculiarities of the $\mathrm{H}^{+}$emission which can probe the very surface.

\section{2 - EXPERIMENTAL}

Production and acceleration of hydrogen clusters from the $800 \mathrm{KV}$ COCKROFT-WALTON of the institut de physique nucléaire de Lyon have already been described in previous publications $/ 6 / / 7 /$. The optics of the beam line has been improved with a more focused beam due to two quadrupole triplets allowing a target spot approximatively $5 \times 8 \mathrm{~mm}^{2}$ without collimators. Contaminants or leak beams /7/ are more easily removed using microslits about 100 um diameter located $20 \mathrm{~mm}$ apart from the target. No significant modifications of the conventional electronics system have to be reported $/ 2 /$. The main features of the time of flight (TOF) set-up for secondary ion detection are a $2 \mathrm{~mm}$ acceleration gap between the biased target $( \pm 4 \mathrm{KV})$ and a $98 \%$ transmission grid at ground, a shielded drift zone, $115 \mathrm{~mm}$ long, ending with the grounded front face 
of the microchannel plate (MCP) assembly $(\phi 18 \mathrm{~mm})$. We have already emphasized the restrictions on the target thickness when detecting positive ions : the start signal can only be obtained from the transmitted fragments reaching a surface barrier detector (SBD). The minimum deposit thickness required for avoiding inhomogeneities restricts the mass range of the incident particles. Our CsI deposits on $80 \%$ transmission grid, formvar coated, have typical thicknesses of $25 \mu \mathrm{g} / \mathrm{cm}^{2}: \mathrm{then}^{2}$ the highest detected mass is 61 at $600 \mathrm{keV}$.

In contrast to what has been observed with negative ions $\left(I^{-}\right) / 2 /$ the positive ion yield does not change with the nature of the substrate. This has been verified using Ar incident ions at 16 $\mathrm{MeV}$ : in that case both thin targets and deposits on bulk substrates can be analyzed taking the start signal from a thin carbon foil interposed on the incoming beam $/ 8 /$. The agreement has always been found satisfactory.

From a time digital converter (TDC) connected to a VME 10 MOTOROLA computer, up to 255 events corresponding to a single cluster interaction can be detected and the yield of each detected mass is obtained from the related peak area divided by the start number recorded. The yield values are only corrected for the distribution of emitted ions per incoming particle assumed to be poissonian $/ 9 /$.

Finally the electronic stopping power values for the constitutive protons have been taken from the tables of ANDERSEN and ZIEGLER /10/, applying the BRAGG'S rule for the compounds and the solid state corrections when necessary. Even for the highest mass 61 , the electronic stopping is still larger than the nuclear stopping (about one order of magnitude).

\section{3 - POSITIVE ION YIELD CORRELATION WITH THE ENERGY DEPOSIT OF THE PARTICLE}

\section{1. - Additive stopping and cluster stopping}

All our previous experiments have been performed at a given energy ( $600 \mathrm{keV})$. Under these conditions, the only accessible parameter is the electronic additive stopping power $S$ for the $\mathrm{H}_{n}^{+}$cluster ( $\mathrm{n}$ times the stopping for the proton of the same velocity). As it is shown on figure 1 , the yield of either $\mathrm{Cs}^{+}$or $\mathrm{H}^{+}$from CsI exhibits a linear variation in a Log-Log plot. It can be noted that the slopes are different above $v_{0}$ but the two curves have a definite change for about the same velocity, noticeably below $v_{0}$.

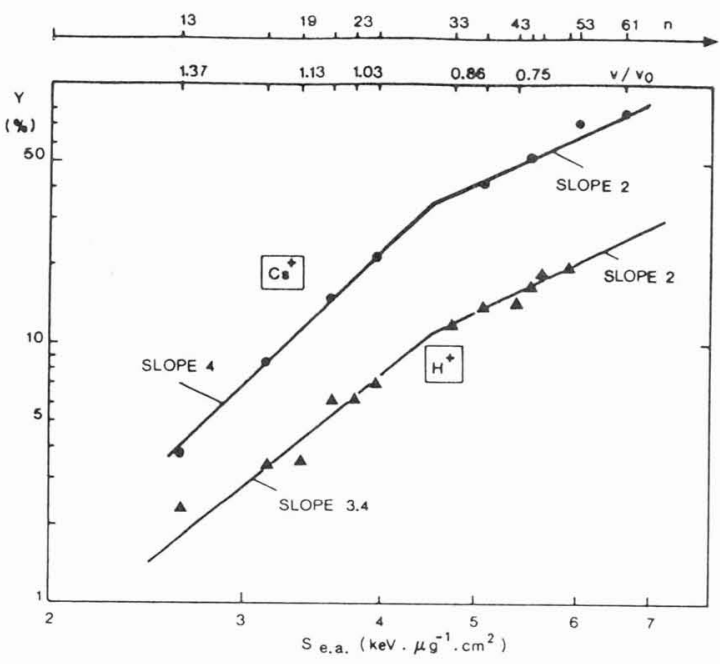

Fig.1 - Yield variations of $\mathrm{Cs}^{+}$and $\mathrm{H}^{+}$as a function of the electronic additive stopping power for $600 \mathrm{keV} \mathrm{H}{ }_{n}^{+}$clusters. (masses and relative velocity are indicated).

Without any further explanations of what should be the real stopping for a cluster, except it should be equal or higher than $S_{\text {e.a. }}$, one can express it from an enhancement factor $R(n)$ depending on $n$. Then if $S_{H_{n}}=R(n) \cdot n . S p$ for a given $n$, the $Y$ yield should be correlated to Sp - Since our velocity range is ${ }^{n}$ limited, the most representative evolution has been taken from $\mathrm{H}_{17}^{+}$and $\mathrm{H}_{13}^{+}$for which values above $v_{0}$ can be obtained. This is represented on figure 2 from wich it 17 appears 13 that 
$Y \propto[R(n) \cdot n \cdot S p]^{2}$. Then one has to relate $S_{H_{n}}$ to $n$. Sp through a physical explanation of $R(n)$.

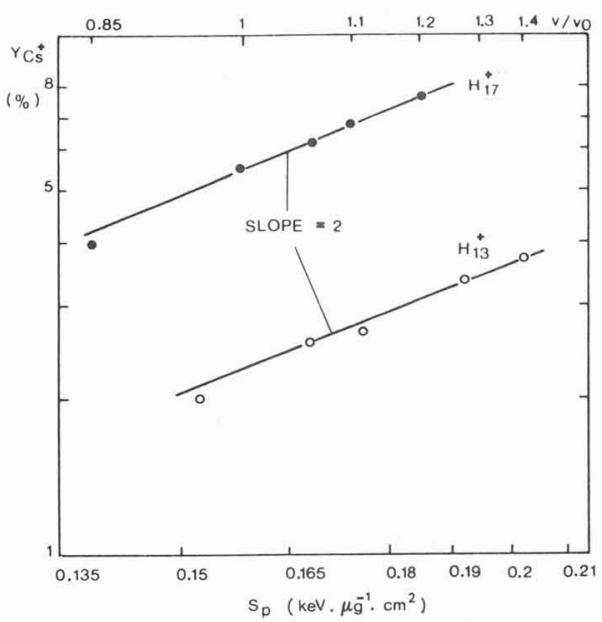

Fig.2 - Yield variations of $\mathrm{Cs}^{+}$as a function of the proton stopping when varying the velocity of $\mathrm{H}^{+}{ }_{17}+$ and $\mathrm{H}_{13}^{+}$

As for monoatomic ions, the stopping power of a given material for a cluster results from knock-on collisions (close collisions) and from collective excitation modes of the electronic system (distant collisions). It is well known that characteristic distances are associated to these effects with $R_{\text {close }}=\hbar / m v$ (typically $0.1 A^{\circ}$ ) and $R_{\text {distant }}=v / \omega_{p}$ (typically 1 to $10 A^{\circ}$ ) - $\hbar$ being the Planck constant, $m$ the electron mass, $v$ the particle velocity and $\omega$ the plasma frequency of the medium For the particular case of clusters, their penetration in condensed matter leads to a stripping of valence electrons and the breaking of chemical bonds. Individual ions repel each other from the Coulomb repulsion until their interatomic distance $R_{i j}$ exceeds the dynamic screening /distance $R_{d}$. Various expressions of the stopping power are associated to the $R_{i j}$ values :

$-\mathrm{R}_{\mathrm{ij}}<\mathrm{R}$ close : the cluster acts as a charged point and $\mathrm{Z}_{\text {eff }}^{2}=\left(\Sigma_{\mathrm{i}} z_{\mathrm{i}}\right)^{2}$ and $\mathrm{S}_{\mathrm{H}_{\mathrm{i}}}=\left(\Sigma_{\mathrm{i}} \mathrm{Z}_{\mathrm{i}}\right)^{2}$. Sp $-R_{i j}>R_{\text {distant }}$, each particle of the cluster has an independant behaviour and $z_{\text {eff }}=\sum_{i}\left(z_{i}\right)^{2}$ and $S_{H_{i}}=\sum_{i}\left(z_{i}\right)^{2} S_{p}$

$-\mathrm{R}_{\text {close }}<\mathrm{R}_{\mathrm{ij}}<\mathrm{R}_{\text {dist. }}$ : according to LINDHARD and WINTHER/11/

There is an equipartition between the two types of collisions and

$$
\mathrm{s}_{\mathrm{H}_{\mathrm{i}}} \simeq \frac{1}{2}\left[\left(\Sigma z_{\mathrm{i}}\right)^{2}+\Sigma\left(z_{\mathrm{i}}\right)^{2}\right] \mathrm{s}_{\mathrm{p}}
$$

which has been experimentally confirmed by BRANDT et al. $/ 12 /$ for $\mathrm{H}^{+}$and $\mathrm{H}^{+} 3$

This qualitative picture would be in agreement with the detailed expression given by BRANDT and RITCHIE $15 /$ for a dicluster if it can be extended to $n$ constituents with the form :

$$
S_{H_{n}}=S_{p}\left[n+\frac{2 n(n-1)}{2} G\left(\frac{|R| \omega_{p}}{v}\right)\right.
$$

$|\mathrm{R}|$ is the value of the interatomic distance when averaged over all the possible orientations of the cluster. If the variation of the $G$ function is still comparable to the form given in ref./12/ and represented on figure 3 , 


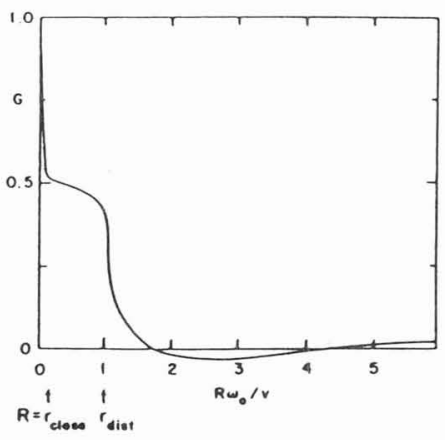

Fig. 3 - G function variation as a function of the reduced interparticle distance (from ref./12/).

$$
\text { when } R_{\text {close }}<|R|<R \text { distant one has } S_{H_{n}}=\frac{1}{2}\left(n+n^{2}\right) S_{p}
$$

and when $|\mathrm{R}|>\mathrm{R}_{\text {distant }}, \mathrm{S}_{\mathrm{H}_{\mathrm{n}}}=\mathrm{n}$. $\mathrm{S}_{\mathrm{p}}$, the additive stopping

\section{2. - "Efficient " mean cluster stopping}

$$
\text { 3.2.1. }-v>v_{0}
$$

The exact determination of $S_{H_{n}}$ cannot be extracted from our experimental results. Moreover what has to be considered is not the total energy loss of the particles but the amount of energy required for producing a detectable emission yield. Of course nothing can be observed from an isolated proton interaction.

Such an "efficient" energy deposit along the cluster trajectory can be sketched as on figure 4 from the integral of the curve as a function of the distance from the surface. At the $d_{r d}$ depth,

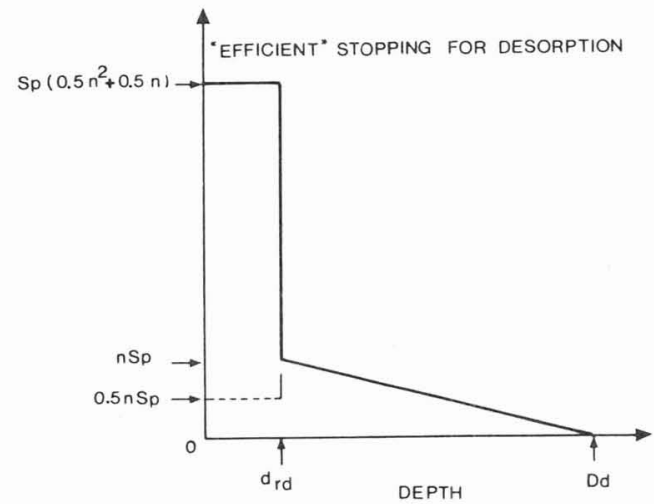
Fig. 4 - Sketch of the " efficient " energy deposit variation for a $\mathrm{H}_{\mathrm{n}}+$ cluster as a function of the
penetration depth.

the interatomic distances reach the value $R$ distant : if the equipartition rule applies on that depth and the stopping can be considered as fairly constant and equal to $S p\left(0.5 n^{2}+0.5 n\right)$. Behind this value the stopping can be considered as additive but due to the separation of the individual tracks, there must be a decrease of the efficent energy deposit until the $D_{d}$ depth is reached. This distance $D$ sets the limit of the desorption phenomenum either because no cumulative effect can occur or simply because no matter can be ejected from such a depth. The consequence of the existence of these two regimes is that we can only correlate the yield to a mean stopping for the cluster with a new partition between close and distant collisions and $R(n)=x n+(1-x)$. As a consequence of the quadratic dependence observed on figure 2 , the best fit is obtained for $R(n)=0.1 n+0.9$ in the velocity range above $v$. If this interpretation is correct, then one must also find a quadratic dependence of the yield as a function of $R(n)$. $n$ at a given velocity. Indeed, the agreement shown on figure 5 above and slightly below $\mathrm{v}_{n}$, for masses $13,17,19$ and 21 can be considered as satisfactory. 


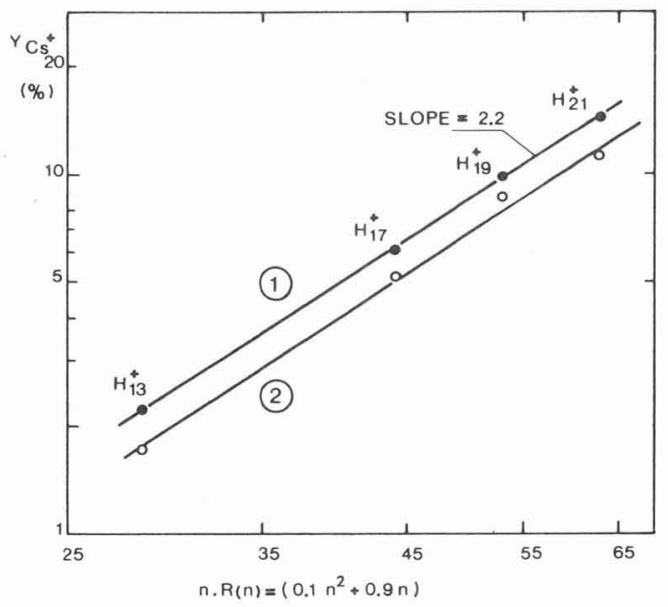

Fig. 5 - Yield variation of $\mathrm{Cs}^{+}$. as a function of $n \cdot R(n)=0.1 n^{2}+0.9 \cdot n$ for the velocity (1):0.234 $\mathrm{cm} / \mathrm{ns}$ (2) $0.214 \mathrm{~cm} / \mathrm{ns}$.

\subsection{2. $v<v_{0}$}

Using the same procedure (experiments respectively at $n$ and $S_{p}$ constant), the most interesting result at $\mathbf{n}$ constant is that the quadratic dependence is still verified as evidenced on figure 6. Then, the most plausible hypothesis consists to admit that there is a saturation of the enhancement factor $R(n)$ at some critical velocity value below $v_{0}$. From the curve of the figure 1 ,

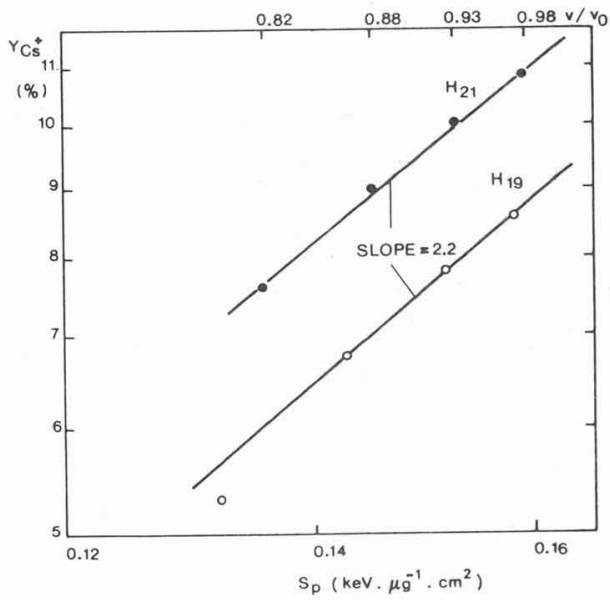

Fig. $6-$ Yield variation of $\mathrm{Cs}^{+}$as a function of the proton stopping when varying the velocity below $\mathrm{v}_{0}$ of $\mathrm{H}_{21}^{+}$and $\mathrm{H}^{+}{ }_{19}$

the slope change takes place for $v \simeq 0.2 \mathrm{~cm} / \mathrm{ns}$. For a cluster with a given mass, the $R(n)$ value will be those of the cluster which has the same total energy at the critical velocity. From the data of the figure 6 , for the extreme values of $\mathrm{v} / \mathrm{v}_{\mathrm{o}}, 0.82$ and $0.98, \mathrm{R}(\mathrm{n})$ for $\mathrm{H}_{21}$ will vary between 3 and 2.58 and for $\mathrm{H}_{19}$ between 2.8 and 2.42. Taking into account this variation of $R(n)$ with the velocity gives a slope closer to the expected value of 2 . One can also expect to verify the quadratic dependence of $\mathrm{Y}$ as a function of $\mathrm{R}(\mathrm{n}) \cdot \mathrm{n}$ at a given velocity. This is shown on figure 7 as 


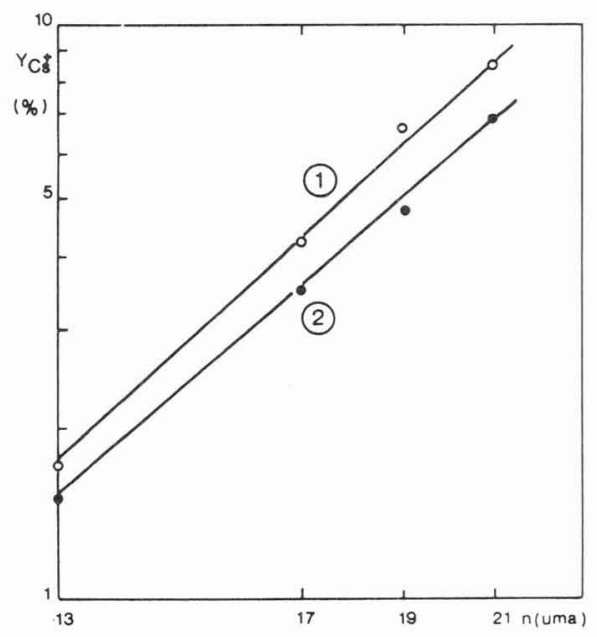

Fig. 7 - Yield variation of $\mathrm{Cs}^{+}$as a functiuon of $\mathrm{n}$ for $1 \mathrm{v}=0.188 \mathrm{~cm} / \mathrm{ns}$ and $2 \mathrm{v}=0.175 \mathrm{~cm} / \mathrm{ns}$. The straight lines are for the $n^{3.2}$ and $n^{3.1}$ variation (expected values of $[R(n) . n]^{2}$ ) a function of $\mathrm{n}$ in the mass range 13 to 21 for the velocities 0.188 and $0.175 \mathrm{~cm} / \mathrm{ns}$. With the hypothesis of a saturation in the enhancement factor, at a given velocity an identical partition between close and distant collisions, is always found. This is coherent with the conservation of the mean interprotonic distance observed above $v_{0} / 5 /$ which should exist below $v_{0}$ due to the existence of the static screening distance.

Then, with these new values of the mean stopping for the cluster, a quadratic dependence of the yield as a function of the stopping power is observed above and below $v_{0}$. As a second important result it is clear that collective effects persist below $v_{0}$ : However the critical velocity for which a change is observed is noticeably lower $(\sim 0.2 \mathrm{~cm} / \mathrm{ns})$.

\section{3. - Change of the efficient cluster stopping with the emission depth $-\mathrm{H}^{+}$emission}

\subsection{1. - v > $\mathrm{v}_{0}$}

According to the previously $R(n)$ values, the $\log -\mathrm{Log}$ plot of $\mathrm{Y}_{\mathrm{H}^{+}}$as a function of $S$ for a given mass would exhibit a slope of about 1.8 . As it can be seen on figure 8 , there is a Befinite trend for lower values, indicating a larger contribution of distant collisions. The ORSAY group has reported that under heavy ion bombardment, $\mathrm{H}^{+}$is emitted from the very surface $/ 14,15 /$. However, significant yield differences can be found between materials according to their respective hydrogen surface-bulk concentration ratio (8). For example, the $\mathrm{H}^{+}$yield variation as a function of $\mathrm{S}_{\text {is }}$ is very different for phenylalanine (8)(16). In that case, an emission from the "bulk" is pointed obut, governed by a different mecharism of ejection. Then, if we assume that $\mathrm{H}^{+}$comes essentially from an hydrocarbon adsorption layer, one can test if the emission depth is confined into the limits of $d_{\text {rd }}$ where the stopping could be deduced from the equipartition rule. In that case, still for a Log- $\mathrm{Log}$ plot of $\mathrm{Y}_{\mathrm{H}^{+}}$as a function of $\mathrm{S}_{\mathrm{H}}$ a slope value of about 1.35 can be deduced from the data $2^{f}$ the figure 1 . As a matter of fact, at a given velocity, the variation of $\mathrm{Y}_{\mathrm{H}^{+}}$as a function of $\left(n^{2}+n\right)$ in a Log-Log plot, leads to a slope close to the expected value as it appears on figure 9.

\subsection{2. $v<v_{0}$}

Below $v_{0}$, at constant velocity, $\mathrm{Y}_{\mathrm{H}^{+}}$must be plotted as a function of $\mathrm{S}_{\mathrm{H}}$ as determined with the hypothesis of the saturation of the enhancement factor. This is represenfed on figure 10 for $v=0.188 \mathrm{~cm} / \mathrm{ns}$, where the slope value in a Log-Log plot is also very close to the expected 1.35 value. Then, as for $\mathrm{Cs}^{+}$, there is also no change above and below $\mathrm{v}_{0}$, in the dependence of the yield on $\mathrm{S}_{\mathrm{H}_{\mathrm{n}}}$, provided it is determined on the proper emission depth. 


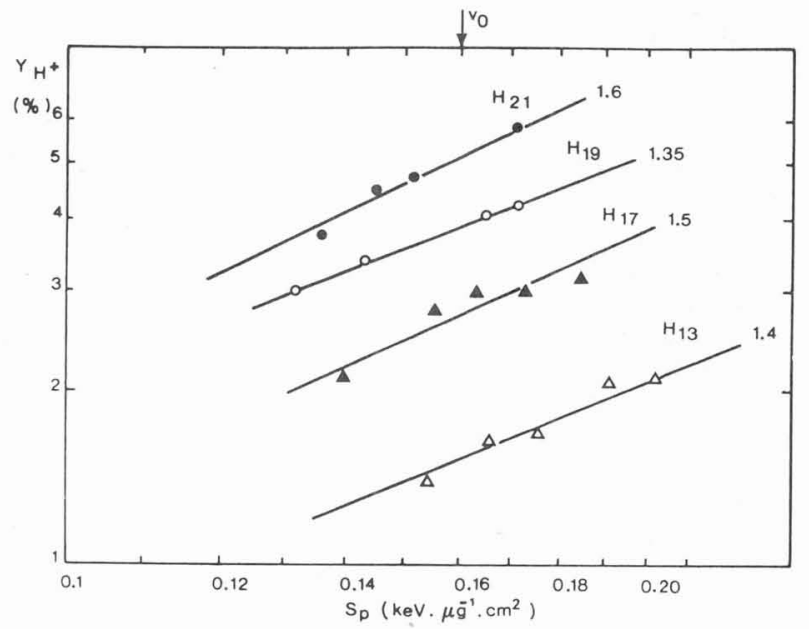

Fig. 8 - Yield variation of $\mathrm{H}^{+}$as a function of the proton stopping when varying the velocity of the indicated clusters.

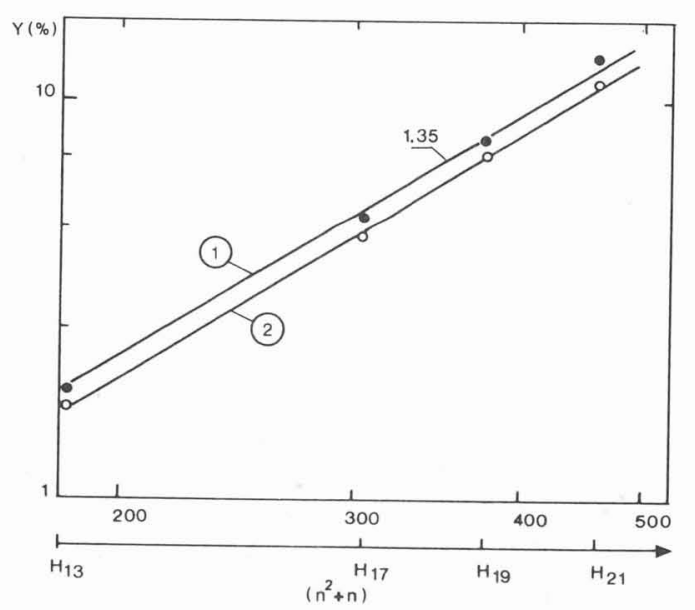

Fig. 9 - Yield variation of $\mathrm{H}^{+}$as a function of $\left(n^{2}+n\right)$ (1) $: v=0.235 \mathrm{~cm} / \mathrm{ns}$ (2) $v=v_{0}$

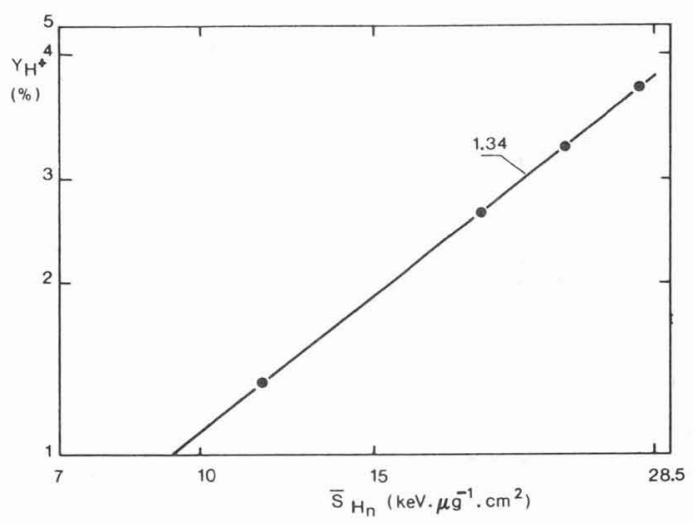
Fig. $10-$ Yield variation of $\mathrm{H}^{+}$as a function of $\overline{\mathrm{S}_{\mathrm{H}_{n}}}(\mathrm{v}=0.188 \mathrm{~cm} / \mathrm{ns})$ as determined from the $\mathrm{R}(\mathrm{n})$
saturation $\left(v<v_{0}\right)$ - masses 13 to 21$)$. 
Since no such experiments have been made for the higher masses (above 33), one can at least obtain new qualitative informations about the partition between close and distant collisions when changing the velocity below $v$. First of all, the determination of $R(n)$ from the saturation effect is not expected to change the initial slope but the interesting point is the shift observed from the curve extrapolated from the values obtained at $v>v_{0}$ (figure 11). Correcting the $\overline{S_{H}}$ values to fit a single curve implies an increase of $R(n)$ or $x$ (distant collisions proportion) as a Hunction of the particle velocity. With the simple picture of a continuous decrease of the collective effects (proportionality to $\mathrm{n}^{2}$ ) from the surface to a given depth (corresponding to the static screening distance), mirrored by an increase of the additive contribution. A crude representation can be made as on figure 12. The right: (a) distribution is for the collective part, going from 0.5 to 0 over the DC thickness while the left. (a) distribution is for the additive part going from 0.5 to 1 in a symmetrical manner. Then it is easy to see that the end position of the hydrogen emission zone (line 1 or 2) will allow to determine the ratio $\frac{x}{1-x}$ from the related areas ratio. For position 1 $A E F G D /(K L M N+K N R P)$ will give value higher than AECD/(KLIJ + KJSP) which is the $\frac{x}{1-x}$ of the saturation effect. For a lower velocity (b), the collective effects distribution decreases more rapidly and the correction is still higher, which is in qualitative agreement with what is experimentally observed. At last a small hydrogen emission depth (line (2) compared to (1) ) implies a higher $\frac{\mathrm{x}}{1-\mathrm{x}}$ ratio.

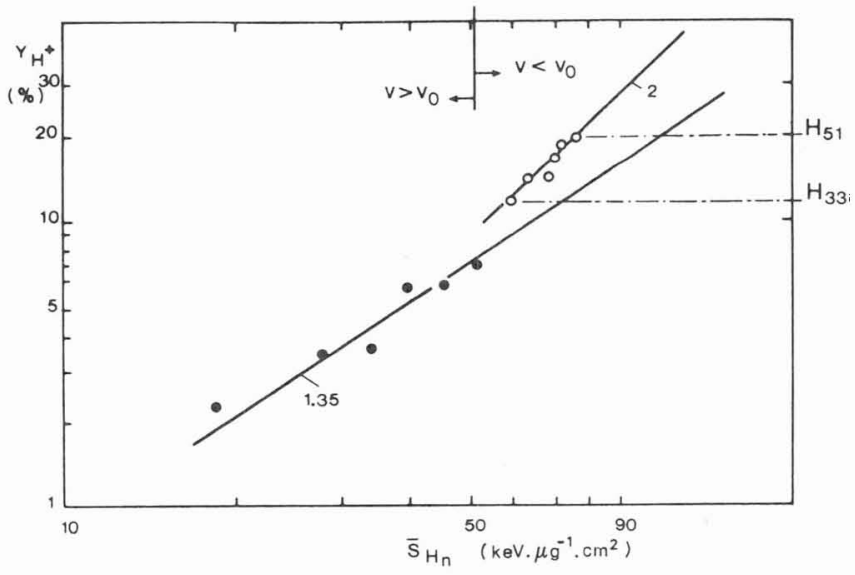

Fig. 11 - Yield variation fo $\mathrm{H}^{+}$as a function of $\overline{\mathrm{S}}_{\mathrm{H}}$ as defined in the text.

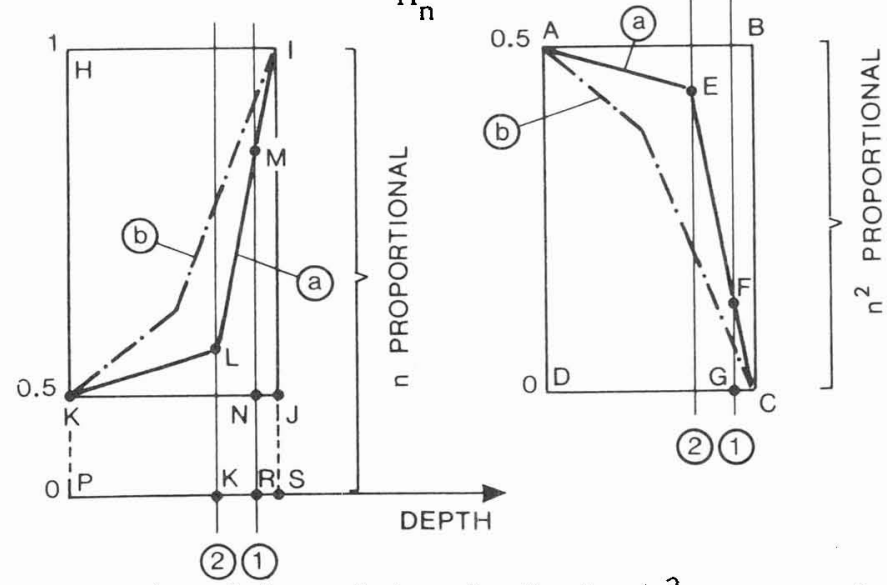

Fig. 12 - Schematic representation of the evolution of collective $\left(\mathrm{n}^{2}\right.$ proportional) and individual ( $\mathrm{n}$ proportional) contributions below $v_{0}-$ (a) and (b) for decreasing velocity. (1) and (2) for two end distributions of hydrogen below the depth PS corresponding to the extinction of the collective effects. 
Of course, such a schematic representation can only give a trend of the effect, qualitatively consistant, but more sophisticated experiments are needed to probe the interaction range. On the other hand, it would be extremely useful to confirm the picture of an $\mathrm{H}^{+}$emission related to an H-rich adsorption layer.

Other materials have to be tested once $H$ depth-profiling has been performed (8).

\section{CONCLUSION}

The emission yield of $\mathrm{Cs}^{+}$and $\mathrm{H}^{+}$from the irradiation of $\mathrm{CsI}$ by $\mathrm{H}_{n}^{+}$clusters at a maximum energy of $600 \mathrm{keV}$ can be correlated to a mean stopping for the cluster. This mean stopping must be associated to a cumulative energy deposit within the cluster track taking into account the emission depth. From our crossed experiments the main conclusion is that the equipartition rule between close and distant collisions seems applicable over a ${ }_{r d}$ depth (corresponding to the dynamic screening distance), for velocities $v>v_{0}$. Below $v_{0}$ it has been shown that there is a decrease but not an extinction of the collective effects. As a function of the mean "efficient " stopping power extracted from the experimental data, both the $\mathrm{Cs}^{+}$and $\mathrm{H}^{+}$emission yield have a constant power dependence above and below $\mathrm{v}$. The quadratic dependence of the $\mathrm{Cs}^{+}$yield has often been reported for monoatomic ions at higher particle velocity, but never at values so close to the BOHR'S velocity. The 1.35 exponent characteristic of the $\mathrm{H}^{+}$emission cannot be presently explained but is very close to the 1.5 value inferred from the results of DELLA NEGRA et al. /14/ using monoatomic ions at higher energy.

\section{REFERENCES}

11/ Thomas, J.P., Filpus-Luyckx, P.E., Fallavier, M. and Schweikert, E.A., Phys.Rev.Lett.55 (1) (1985) 103

/2/ Thomas, J.P., Oladipo, A. and Fallavier, M., Nucl.Instr. and Meth. in Phys. res. B 32 (1988) 354

13/ Salehpour, M., Fishel, D. and Hunt, J., Rap. Comm. Mass. Spec. 2 (1988) 59

141 Salehpour, M., Fishel, D.L. and Hunt, J.E., Inst. J. of mass.spec. and ion processes 84 (1988) R7

15/ Brandt, W. and Ritchie, R.H., Nucl.Instr.and Meth. 132 ( 1976) 43

16/ Moser, H.O., Martin, J. and Salin, R., J.Phys. 38 C2(1977) 215

/7/ Thomas, J.P., Fallavier,M., Filpus-Luyckx, P.E. and Schweikert, E.A., Rad. Eff. 99 (1986) 213

18/ Oladipo, A., Thesis University of LYON (1988) unpublished

19/. Hakansson, P. and Sundqvist, B., Rad. Eff. 61 (1982) 179

/10/ Andersen, H.H. and Ziegler, J.F., "Hydrogen stopping power and ranges in all elements" Pergamon Press (1977)

111/ Lindhard, J. and Winther, A., Kgl Danske Videnskab, Mat.Medd. 34 (1964) 4

/12/ Brandt, W., Ratkowski, A. and Ritchie, R.H., Phys.Res.Lett. 33, 22 (19784) 1325

113/ Mazuy, B., Thesis, University of LYON (1987) unpublished

1141. Della Negra, S., Le Beyec, Y., Monart, B., Standing, K. and Wien, K., Phys.Rev.Lett. 58, 1 (1987) 17

115/ Della Negra, S., Becker, O., Cotter, R., Le Beyec, Y., Monart, B., Standing, K. and Wien; K., J. de phys. (1987) 151,

/16/ Thomas, J.P., Oladipo, A. , and Fallavier, M., to be published 